\title{
DEPORTE Y POLÍTICA. LA LUCHA CANARIA \\ ENTRE DOS REGÍMENES: \\ II REPÚBLICA Y FRANQUISMO
}

\author{
Javier Ramos Benítez* \\ jrramos@ull.edu.es \\ Universidad de La Laguna
}

\section{RESUMEN}

El presente artículo se adentra en los efectos que el estallido de la guerra civil espańola tuvo para la lucha canaria. Partiendo de los momentos previos al alzamiento, y adentrándose en los prolegómenos de la maltrecha cita olímpica prevista para celebrarse en Barcelona en 1936, se hace un recorrido por los percances que padecieron algunos luchadores en el momento del levantamiento militar, durante el desarrollo de la contienda y los efectos colaterales que la victoria del bando fascista tuvo sobre sus vidas una vez finalizada la guerra. Desde esta perspectiva el deporte se convierte en reflejo de la realidad social vivida en Canarias como consecuencia del conflicto militar. A través de las vicisitudes de los protagonistas de un deporte tradicional como la lucha canaria se atiende a una vía de conexión entre el ámbito de la política y el deporte desde una perspectiva historicista.

Palabras clave: deporte, lucha canaria, II República, franquismo, Olimpiada Popular Barcelona 1936.

\author{
SPORT AND POLITICS. CANARIAN WRESTLING \\ BETWEEN TWO POLITICAL REGIMENS: \\ II REPUBLIC AND FRANQUISMO
}

\section{Abstract}

This paper investigates the effects that the outbreak of the Spanish Civil War had on the traditional sport of Canarian wrestling. Starting from the time before the uprising and studying the factors involved in the failed bid to host the Olympics in Barcelona in 1936, this paper describes the misfortunes and setbacks suffered by some Canarian wrestling at the time of the military uprising, during the Civil War and after the victory of fascist forces on their lives. From this perspective, sport reflected the social reality in the Canary Islands as a consequence of the military conflict. Through the vicissitudes of the lives of the protagonists of a traditional sport like Canarian wrestling, the link between politics and sport is analyzed from a historical standpoint.

Keywords: sport, Canarian wrestling, II Republic, Franquismo, popular Olympics Barcelona 1936. 


\section{METODOLOGÍA}

El método de investigación al que se ha recurrido para la realización de este artículo es el método historiográfico, siendo su objetivo último ahondar en la conexión entre política y deporte. El objeto de este trabajo se circunscribe a un periodo histórico concreto de la lucha canaria donde se profundiza en las vicisitudes que padeció el mundo de la lucha canaria a raíz del establecimiento de un régimen dictatorial en España. Así mismo, se atiende a los momentos previos a la insurrección militar focalizando la atención en la propuesta de realización de una olimpiada obrera a celebrar en Barcelona durante los últimos momentos del periodo republicano y donde la lucha canaria tuvo presencia. Así pues, el principal recurso investigador de carácter historiográfico manejado han sido fuentes primarias sobre el objeto de estudio de este trabajo, lucha canaria, República y franquismo.

En relación con las referencias bibliográficas, en un sentido amplio, se ha atendido a aquellas fuentes que tratan el tema del deporte en general pero que se interesan por los aspectos que relacionan más directamente el deporte y la política. En cambio, desde una óptica concreta, se ha prestado atención a las fuentes en las que figura la lucha canaria como asunto principal para indagar en sus posibles relaciones con la política. Dentro de este ámbito hay que aclarar algunos puntos:

- La marcada tendencia historicista de los trabajos que tienen la lucha canaria como objeto de estudio, un punto de vista que se ha adoptado en esta investigación al preocuparse por aquellos aspectos pretéritos en conexión con el mundo de la política. El recurso a tales pautas se convierte en imprescindible si se atiende a la evolución que este objeto de estudio ha sufrido a lo largo de los siglos, pasando de un mero juego, actividad deportiva con fines altruistas, un simple divertimiento, a configurarse como un deporte moderno donde los fines se convierten en intereses, se organizan, reglamentan, etc.

- La escasez de trabajos que profundizan en los aspectos actuales de la lucha canaria, con excepción de los trabajos biográficos centrados en figuras relevantes del mundo de la lucha o de tratados teórico-técnicos deportivos.

\section{LUCHA CANARIA Y II REPÚBLICA}

El DEPORTE DURANTE LA II REPÚBLICA

La II República se marcó como objetivo fundamental un cambio de las estructuras fundamentales de España. En palabras de Ortega y Gasset, el nuevo régimen alumbraba «un nuevo amanecer» (Carr, 1991), con el fin de solventar por

* Departamento de Derecho Constitucional, Ciencia Política y Filosofía del Derecho. 
la vía reformista los enquistados problemas que condicionaban el proceso de modernización social y económica del país (Ferrer, 1993). A la postre una intención ante la cual el sistema político se mostró incapaz de actuar eficientemente acorde con sus planteamientos esenciales (Varela, 1978). Carentes los gobernantes que toman el poder tras 1931 de la suficiente pericia política y de un proyecto donde se definiera, de manera precisa, la agenda republicana y que contase con una base estable de apoyo social y político, las posibilidades de éxito en la instauración de un régimen democrático en España en concordancia con los planteamientos ideológicos de las principales democracias occidentales toparon con un escenario complicado y complejo. Desde el descalabro de la reforma agraria, el incremento de los problemas económicos potenciados por la crisis internacional del 29 con su consecuente efecto negativo en las cifras de empleados, una panorámica política institucional con marcada tendencia a la inconsistencia, la volatilidad de los procesos electorales, la persistencia del poder de los poderes fácticos conservadores como el ejército, clero o grandes propietarios fueron algunos de los elementos que coadyuvaron al ocaso del proyecto republicano (Carr, 1991; Brito, 1989).

En este contexto de cambio de régimen el proyecto deportivo republicano se presentaba condicionado por los vaivenes políticos y sociales que asolaron al país desde finales del siglo xix. Hacia finales de dicha centuria, la práctica deportiva era considerada un coto de los estratos sociales altos mientras que los grupos menos favorecidos encontraban en las fiestas locales su pasatiempo predilecto. La aristocracia española del momento, como grupo social, se caracterizaba por un conservadurismo alejado del ideal burgués de progreso y modernización. No obstante, en lo referente al deporte la aristocracia española halló en el modelo aristocrático inglés un patrón a seguir. En este contexto, jugó un papel fundamental la actitud del rey Alfonso XIII, un entusiasta del deporte, sobre todo de la caza. La afición del monarca por la actividad deportiva se vio acompañada por su predisposición a favorecer que España fuera sede de eventos deportivos de transcendencia internacional, actitud que se vio reflejada en su propio nombramiento como presidente honorífico de la fallida candidatura de Barcelona a los Juegos de 1924.

En un sistema educativo que por entonces presentaba fuertes carencias, el asunto de la educación física en las escuelas no podía ser un tema de interés. La educación física contaba con presencia tan solo en reducidos espacios elitistas. En este ámbito hay que destacar la creación de la Escuela Central de Profesores de Gimnasia en 1885 durante del reinado de Alfonso XIII, si bien para el comienzo de su andadura se tuviera que esperar hasta 1887, momento de su inauguración. Debido a razones económicas la escuela tendría una breve existencia de tan solo cinco años.

La creación de la Escuela Central de Gimnasia en Toledo, en 1919, supuso la apertura de la formación física como actividad a los grupos menos favorecidos, que hasta entonces solo podían gozar de sus beneficios como miembros del ejército, al contrario de los grupos aristocráticos. Con este centro se ofrecía a los miembros de las fuerzas armadas la posibilidad de mejorar su estado físico, a la par que se ampliaban a la ciudadanía en general las competencias físico-deportivas. La intención última que se pretendía lograr con la creación de dicho centro era contar con profesores de educación física en el ejército, así como con personal cualificado en la 
enseñanza pública que instruyesen a las generaciones más jóvenes en los hábitos del deporte, por ello los maestros que realizaban el servicio militar recibían una formación específica sobre la materia (González, 2002). No obstante, cabe señalar que en la práctica la presencia de la educación física en las escuelas nunca contó con el respaldo político necesario para implementar un programa de educación física de calidad a nivel nacional, pasando a formar parte la educación física de una materia, de entre otras, que se impartía de forma precaria (Pujadas, 2011)

Desde finales de la década de los 20 hasta la llegada de la República, la aristocracia, ya en plena decadencia, continuó haciendo acopio del hecho deportivo. A pesar de ello, se trata de un momento en que el deporte español comenzó a desarrollar un ciclo modernizador y de adaptación a los dictados de la mercantilización, como atestiguan el boxeo, el ciclismo o el fútbol. A lo largo de la dictadura de Primo de Rivera el espectáculo deportivo en los núcleos poblacionales se adaptó a los dictados del mercado y se contó con una normativa en la que asentar su incipiente proceso de profesionalización. Durante este periodo se desarrollan algunas de las peculiaridades deportivas que seguirán su curso a lo largo de periodo republicano, como la tendencia al asociacionismo deportivo, el aumento del número de deportistas y la implantación de nuevos deportes.

Dentro del paradigma de los nuevos impulsos ideológicos que circundan a España, el deporte fue sometido a un proceso de democratización y socialización. El movimiento olímpico no escaparía a dicha corriente y el control aristocrático del olimpismo cedió paso a una nueva concepción del deporte de tendencia popular, como medida más significativa cabe señalar la oposición del Gobierno republicano a que España tomara partido en las olimpiadas alemanas de 1936 en sintonía con los postulados internacionalistas y autóctonos de los movimientos populares de la década de los 30 . Un periodo en que el deporte y sus instrumentos de sociabilidad fueron conducidos hacia la popularización y la democratización impulsados por el incremento del asociacionismo entre los estratos populares y obreros (Pujadas, 2011). A partir de entonces se produce una verdadera inmersión de los estratos menos favorecidos en el mundo del deporte, momento en que resulta efectiva la democratización del deporte en consonancia con los principios ideológicos del nuevo régimen. La incipiente conversión del deporte a los dictados del mercado, al profesionalismo, al deporte espectáculo repercutieron no solo en el número de personas que practicaban deporte, sino también en el número de aficionados al deporte. Sin duda, un fenómeno que se vio potenciado por un contexto social libertario en que el asociacionismo deportivo se constituyó como el centro del proceso. En suma, a lo largo de esta fase los grupos menos favorecidos accedieron al deporte, despojando de tal privilegio a la aristocracia, ayudados por la aparición del asociacionismo deportivo, que contó con la legitimidad del nuevo régimen para expandir la práctica deportiva y los ideales en que se sustentaba el régimen republicano como el antifascismo, el pacifismo, la justicia social, la igualdad (Plazas, 2018).

Las políticas deportivas implementadas por los gobiernos republicanos consideraron la educación física y el deporte como materia complementaria de la enseñanza de los jóvenes siguiendo los novedosos planteamientos pedagógicos liderados por la Institución Libre de Enseñanza (González, 2002; Pujadas, 2011; Campi- 
llo et al., 2018). Bajo el supuesto de que las actividades en contacto con la naturaleza y las físico-deportivas poseían un gran alcance educativo, la Institución Libre de Enseñanza abogaba por que se implementara la condición pedagógica de la educación física en los colegios desdeñando del modelo rígido de gimnasia germánico. No obstante, hay que señalar que en el caso de España, la educación física como asignatura nunca contó con un apoyo certero ni por parte de las autoridades educativas ni de la población, más bien fue víctima del descrédito y del desprestigio, aspecto este que comienza a superarse con la llegada de la democracia a finales de los 70 (García, 1990).

\section{LA LUCHA CANARIA SOBRE LA ARENA REPUBLICANA}

En los momentos previos al advenimiento de la II República destacó el comportamiento de los luchadores del equipo de San José de Las Palmas de Gran Canaria, quienes, sustentados en un planteamiento cooperativista, decidieron sufragar la financiación del equipo o llevar a cabo la confección de sus equipajes junto con sus seguidores. Esta actitud no fue casual y respondía a la arraigada conciencia social de los habitantes del barrio de San José, de condición social baja. De este modo, el colectivo se imbricó en los asuntos políticos, culturales, sociales o deportivos emprendiendo la acción social a través de la demanda de mejoras en infraestructuras (Padilla, 2004). El 14 de abril de 1932, la lucha canaria participó en la conmemoración del primer aniversario de la II República con la disputa de una luchada en la plaza de toros de Santa Cruz de Tenerife. Merece atención la figura de Emilio Rivero Rodríguez, quien participó en las tareas organizativas de dicha celebración y cuya vida transcurrió cerca de los terreros como luchador, como organizador o enseñando, además de ser un personaje del mundo de la lucha canaria que desarrolló una carrera pública destacada en su pueblo, como juez de paz y alcalde de Tegueste, durante el régimen republicano. La presencia de otra personalidad de la política canaria en el mundo de la lucha canaria se sucede a finales de 1933. En este caso, con motivo del homenaje al político federalista canario José Franchy Roca, fundador del Partido Republicano Federal Canario, diputado a Cortes por Las Palmas de Gran Canaria, fiscal general del Estado y ministro de Industria y Comercio durante la II República, se celebró un acto de reconocimiento que congregó a gran número de aficionados tanto por aspectos deportivos como por el carisma que irradiaba la figura del homenajeado (Hernández y Sánchez, 1979; Henríquez, 1986).

En la primavera de 1935 se celebró en Santa Cruz de Tenerife un festival de representaciones folclóricas con motivo de sus fiestas. Entre otros juegos y deportes vernáculos se exhibieron encuentros de lucha canaria. El acto se convirtió en un enardecimiento de la canariedad posibilitado por una forma de Estado que alentaba los valores del sistema democrático (Morales y Palenzuela, 2004) y fomentó la descentralización de la distribución territorial del poder atendiendo al hecho diferencial que demandaban algunas de las comunidades regionales que configuraban España (Varela, 1976; Payne, 2005). 


\section{LUCHA CANARIA Y FRANQUISMO}

La imposición del régimen franquista en España tras el derrocamiento de la II República como colofón a una cruenta guerra civil de tres años conllevó la represión de las libertades públicas. Además, se produjo un proceso de persecución hacia aquellos que fueran identificados con el bando republicano, así como hacia cualquier planteamiento ideológico que no comulgara con los impuestos por el franquismo. El afán de control de la sociedad civil dentro de una concepción organicista de la sociedad supuso también el control mediante previa autorización del desarrollo de toda actividad ciudadana. En este contexto, los medios de comunicación y la educación fueron ámbitos en los que el franquismo puso especial énfasis en dirigir. La intención era utilizar ambas vías como medio de transmisión del credo franquista, centrado en postulados teológicos y nacionalistas, dando comienzo a un proceso de legitimación del nuevo régimen desde los mass media y el sistema educativo. El adoctrinamiento de niños y jóvenes corrió de la mano del clero y de la Falange, a los que les fue encomendada la tarea de dirección de la enseñanza pública nacional.

Dentro de este afán controlador impuesto por el nuevo régimen dictatorial, el deporte iba a ser absorbido por la vorágine dirigente impulsada desde Madrid. Para ello se contó con la estructura organizativa aportada por la Falange, que asumió la difusión de una representación simbólica franquista del deporte focalizada en los conceptos de patria, disciplina y juventud masculina (Rodríguez, 2008). En dicha organización recayó la responsabilidad de organizar y dirigir el deporte a través de la recién creada Delegación Nacional de Deportes. A la cabeza de dicha organización se situaba el delegado nacional de Educación Física y Deporte, quien asumía su presidencia. Entre otras funciones, cabe destacar la asunción de la jefatura del Departamento de Federaciones Nacionales lo cual le otorgaba el control del entramado federativo nacional con potestad para nombrar a los máximos responsables directivos de las distintas federaciones, a los componentes de las directivas de las mismas, así como a los presidentes y vicepresidentes de las diferentes federaciones regionales distribuidas a lo largo del territorio nacional. Como expresión máxima de la capacidad de control que se le dispensaba al partido falangista en el ámbito deportivo hay que señalar el derecho de veto ante cualquier medida adoptada por los entes federativos cuando lo considerase oportuno.

La Delegación Nacional de Deportes se constituyó como un organismo dependiente de la Secretaría General del Movimiento, configurándose como muestra de la ideología dominante jerarquizada, un partido único donde se daban cita, junto a falangistas, grupos monárquicos y carlistas. Siguiendo el modelo de los regímenes totalitarios nazi y fascista, el deporte era concebido como un medio para mostrar los valores nacionales de virilidad y la "furia española» a niveles deportivos internacionales, con la intención de edificar un estado de ánimo colectivo de orgullo y unidad nacional (González, 2002; Rodríguez, 2008). En suma, se trató de dar cobertura a la "retórica grandilocuente» en la que el régimen quiso asentar una planificación deportiva poco acorde con el estado real del deporte, afectado por los efectos colaterales de postguerra (Pujadas, 2011). 
La elección del máximo responsable de la Delegación Nacional de Deportes de ningún modo respondía a motivaciones de tipo deportivo, en su mayoría fueron militares, falangistas o políticos a los que se designó para que ocuparan su dirección. Ello tuvo una incidencia negativa en la implementación de políticas públicas deportivas eficaces, ya que no se logró que el deporte fraguara entre los españoles como actividad, ni se consiguieron logros deportivos internacionales susceptibles de ser atribuidos a la gestión de dicha institución deportiva. Sin duda, el escaso interés del régimen por el deporte se manifestó en una dotación presupuestaria muy reducida, lo cual incidió también en el fracaso de las políticas deportivas puestas en práctica por la Delegación Nacional de Deportes. Ello permite hablar de una regresión deportiva que se trató de enmascarar a través del discurso triunfalista propagado desde los mass media (González, 2002; Pujadas 2011).

El papel que jugó el deporte dentro del sistema educativo durante el franquismo se vio condicionado por la percepción que de la enseñanza pública en general tenían los dirigentes franquistas. Implementaron una concepción retrógrada de la enseñanza alejada de las nuevas tendencias pedagógicas que se implantaban en Europa optando por primar los valores tradicionales y religiosos. En cuanto al personal docente, este fue sometido a un riguroso proceso de purga en todos sus niveles. Como había sucedido con el deporte, la enseñanza pública fue controlada por personas cercanas al régimen sin la cualificación necesaria para desempeñar tales tareas pero dispuestas a transmitir los ideales y valores propios del franquismo. Contexto en que a la educación física se le otorgó un papel irrelevante dentro del sistema educativo (González, 2002).

La situación del deporte en la España franquista presenta atisbos de cambio a partir de finales de la década de los 50 con la implementación del Plan de Estabilización en 1959. Momento en que el régimen franquista adopta otra perspectiva sobre el deporte impulsándolo sobre todo en el ámbito de la enseńanza pública (Rodríguez, 2008). La incipiente modernización del país permite que el deporte vaya adquiriendo un mayor reconocimiento y se vaya insertando paulatinamente como elemento de la vida diaria de los españoles.

\section{LA LUCHA CANARIA DURANTE LA DICTADURA FRANQUISTA}

Durante la dictadura franquista una nueva forma de Estado se instauró en Espańa. De una forma de gobierno legitimada en el parlamentarismo con base en los elementos fundamentales que conforman el Estado de derecho (Blas y García, 1988) se pasó a una forma de gobierno caracterizada por el rechazo de tales principios. Del reconocimiento a las singularidades de las diversas nacionalidades que conforman el Estado, a la negación de las mismas bajo la instauración de un régimen centralista (Del Águila, 1993). En este contexto se produce el proceso de ordenación, reglamentación e institucionalización de la lucha canaria. Durante la década de los 40, la lucha canaria sufrió un proceso de transformación que alteró los cimientos del hasta entonces juego popular adaptándose a las pautas propias de los deportes modernos. En este proceso modernizador sin retorno de la lucha canaria se crea- 
ron una serie de instituciones cuyo proceso de regulación y ordenación se prolongó casi 10 años. La lucha canaria, al igual que otras prácticas tradicionales, se amoldó a las exigencias impuestas por una nueva concepción del deporte que se conserva a lo largo del siglo xx. Este proceso de acomodación es imprescindible para la expansión de la práctica de la lucha canaria en el nuevo contexto social (García, 1990) y una muestra de la capacidad de autorregulación del deporte mediante procesos morfogenéticos en concordancia con su medio que posibilita su expansión social (Amador, 1996b). Sin embargo, antes del estallido del conflicto existían demandas para concretar este proceso regulativo. Ejemplos en este sentido pueden encontrarse en la prensa del momento publicada en Gran Canaria (Padilla, 2004). Los primeros intentos organizadores se iniciaron en la década de los 20 pero, ante la imposibilidad de ordenar costumbres y prácticas profundamente arraigadas, fracasaron (Falcón, 2001). La demanda organizativa resurge bajo los auspicios de un régimen con interés en controlar cualquier actividad desarrollada en el ámbito de la sociedad civil, incluido el deportivo, máxime si se atiende a las características que definen a la lucha canaria como deporte autóctono (Falcón, 2001). De tal forma que el franquismo coadyuvó, por interés propio, en la ordenación de la lucha canaria conformándose como un deporte más dentro del movimiento nacional franquista (Morales y Palenzuela, 2004). Las fotografías de los últimos juegos sindicales (1959) organizados por el régimen franquista en Madrid, recogidas en el Cincuentario del Santa Cruz de Tenerife en 2008, ilustran la absorción de una manifestación de la sociedad por el Estado. Una instantánea que muestra a un grupo de luchadores canarios ataviados con la ropa de brega junto a otro grupo de lucha leonesa, evidencia de la asimilación por el Estado de una manifestación de la sociedad civil. En el año 1943 se creó la primera Federación Regional de Lucha Canaria, subyugada a la Federación Española de Luchas (FEL) y con sede en Tenerife. Al asumir la presidencia Domingo Cruz Álvarez al mismo tiempo que ostenta la representación de la Delegación Nacional de Deportes de la Falange Española Tradicionalista y de la JONS, la Federación Española de Luchas actúa como representante de la Delegación Nacional de Deportes. De modo que ambas instituciones hallan representación en Canarias a través de la creación de una Federación Regional de Lucha Canaria vinculada con Madrid. El siguiente paso en el proceso federativo se encaminó hacia la creación de una Federación Regional de ámbito provincial presidida por Fernández Villalba en la provincia de Santa Cruz de Tenerife y por Miranda Junco en la de Las Palmas (Hernández et al., 2000; Morales y Palenzuela, 2004). Las federaciones contaban con plena autonomía en el espacio territorial delimitado por la propia provincia. Por otro lado, cada isla periférica cuenta con una delegación de la federación de su respectiva provincia. Un efecto colateral de la ausencia de una federación de lucha canaria única en las islas fue la proliferación de normas y regulaciones favoreciendo la superposición del factor insular al regional (Morales y Palenzuela, 2004).

Las disputas en los terreros motivadas por la interpretación subjetiva de las normas motivó el establecimiento de un conjunto de normas que acabaran con los altercados. Los luchadores con un patrón de conducta anárquico tuvieron más dificultades para acoplarse a las exigencias del nuevo reglamento, que, además, aplacó los intereses personales de los luchadores y de grupos empresariales que participa- 
ban de las ganancias económicas generadas por la lucha canaria (Falcón, 2001). Durante los años 50, la organización de una luchada requería la aprobación de la respectiva federación de cada provincia. La Federación de Tenerife prohibió la organización de luchadas con los equipos de Gran Canaria o el desplazamiento de sus equipos a dicha isla cuando no mediase una solicitud previa formalizada; mientras que la Federación de Las Palmas censuró los encuentros en los pueblos que careciesen de una inspección federativa previa (Falcón, 2001; Morales y Palenzuela, 2004). Tomando como referente la estructura organizativa del Estado, la distribución organizativa de la lucha canaria tomó forma piramidal y fue controlada desde un centro de toma de decisiones. En el momento de la conversión en deporte moderno, la lucha canaria dio un salto cualitativo en términos de racionalización y especialización en la organización de equipos y federaciones, transformando a los grupos de iguales, reunidos en torno a un juego, en complejas organizaciones asentadas, perfeccionadas, con una delimitación de la división del trabajo compleja, preocupadas por aspectos deportivos y administrativos (García, 1990).

\section{ENTRE EL ÁRBITRO Y EL JURADO. Dos INSTITUCIONES CON CONNOTACIONES OPUES- TAS EN EL UNIVERSO LUCHÍSTICO}

La introducción del árbitro en los terreros fue un aspecto novedoso en la lucha canaria, una figura acorde con los planteamientos de los nuevos dirigentes de la lucha canaria afines al régimen franquista. La presencia del árbitro sustituyó el papel que habían desempañado los jurados, jueces de campo, que cedieron su potestad a un juez único con capacidad de emitir juicios inapelables; en este sentido, la decisión arbitral acabó con los altercados protagonizados por los aficionados ante decisiones ad hoc de jueces de campo proclives a tomar resoluciones consideradas polémicas por el público.

La presencia del árbitro en los terreros estuvo motivada por la influencia de los deportes modernos (Morales y Palenzuela, 2004) y por su adaptación a los requerimientos ideológicos del nuevo contexto político. Sin embargo, los jurados remitían a lo popular, a la toma de decisiones colectivas, aspectos que connotan valores democráticos; en cambio, un árbitro, una única persona que toma decisiones, connota un único poder, una toma de decisiones unipersonales e indiscutibles.

La institución del jurado se instauró con la Constitución republicana de 1931, que en el capítulo vir, precepto 103, otorga a los ciudadanos la posibilidad de participar en la administración de justicia; en suma, una forma de democratización de la justicia. En la lucha canaria, la presencia del jurado se consolidó como una institución fundamental de los terreros desde tiempos inmemoriales, una institución de raíz popular y progresista que chocaba con los nuevos planteamientos retrógrados y reaccionarios del régimen franquista, de ahí que sus representantes en la lucha canaria neutralizaran una institución en la que, siguiendo la tradición, dos de los miembros del jurado tenían como misión abogar en defensa de los luchadores y donde la figura del presidente ostentaba la representación del pueblo. Su actuación se presumía imparcial y ante un empate en el proceso de toma de decisiones, su voto ejer- 
cía como voto de calidad con carácter definitivo; además, era una institución cuyos miembros eran elegidos en base al principio de la mayoría.

A partir del año 1945, el presidente fue impuesto por la federación y elegido entre un grupo de notables, impidiendo que fuese elegido por el pueblo (Sánchez, 1985). De este modo, el jurado fue perdiendo su esencia a lo largo de un proceso que culminó en la década de los 60 .

El árbitro no fue el único elemento exógeno a la tradición luchística que se incorporó al reglamento de 1960. Este mismo reglamento introduce la figura del delegado federativo, verdadero artífice de la desaparición del jurado. La inclusión del delegado federativo se hizo sin la aprobación de los diferentes estamentos luchísticos y sus actuaciones estuvieron en sintonía con los poderes deportivos ubicados en Madrid.

La Constitución espańola de 1978, en su precepto 125, recupera la figura del jurado como vía de participación de los ciudadanos en la administración de justicia. En el caso de la lucha canaria, no se produjo un proceso paralelo de rescate de dicha institución. Los esfuerzos por recuperar el jurado en la lucha canaria a finales de los 70 no fructificaron y, en la actualidad, con la instauración de la democracia, se ha consolidado la figura del árbitro (Sánchez, 1985).

Las Consecuencias de la guerra Civil en la lucha CANaria. El estallido DE LA GUERRA CIVIL Y LOS EFECTOS DE LA CONTIENDA EN EL MUNDO DE LA LUCHA CANARIA

El presente epígrafe se adentra en lo que algunos autores han denominado el lado oscuro de la dictadura. Momento en que se sucede uno de los fenómenos más nocivos de dicho régimen totalitario, la represión sangrienta acaecida con el final del conflicto armado civil (Payne, 2017). El universo del deporte español no permaneció ajeno a los efectos de la represión emprendida por el bando que se había alzado con la victoria de la encarnizada guerra civil. Desde Galicia, donde se hostigó, acosó y asesinó a personas relacionadas con el ámbito del deporte. Allí, la diana fascista apuntó a ciertas familias de tradición liberal y progresista que habían introducido el deporte en Galicia y que habían desarrollado la actividad política a lo largo de la fase republicana induciendo e impulsando la actividad deportiva (Pujadas, 2011). Hasta el otro extremo de Espańa, la meridiana isla de El Hierro, donde la represión franquista se plasma como muestra de las más de 6000 víctimas de la represión en el archipiélago canario. En la isla con menor número de habitantes, las detenciones reflejan solo una parte de lo acaecido, ya que toda su población, con indicios de sospechosa, acabaría siendo víctima indiscriminada de la represión desencadenada en los primeros momentos del ajuste de cuentas político (Cabrera, 1985).

En lo que respecta a la lucha canaria, la primera consecuencia fue la paralización de toda actividad deportiva en los terreros. El alcalde de Tegueste, E. Rivero Rodríguez, fue uno de los luchadores que no pudieron evitar los efectos de la contienda bélica y su desenlace. Por estar comprometido con el ideal republicano permaneció oculto en Santa Cruz de Tenerife desde el comienzo hasta el término del 
enfrentamiento por temor a la represión franquista. Tras el final de la guerra civil fue indultado al no haber cometido delitos de sangre y volvió al mundo de la lucha canaria (Rivero, 2007). No obstante, no todos los luchadores tuvieron igual andadura. En Gran Canaria, algunos de ellos fueron obligados a participar directamente en la guerra, mientras otros fueron recluidos en campos de concentración, como es el caso de Fernando Suárez y Fernando Ríos, que, junto a otros miembros de sus familias, estuvieron prisioneros en el sur de Gran Canaria (Henríquez, 1986). José Santana Florido estuvo seis meses confinado en el mismo campo de concentración y su trágico final fue uno de los momentos más penosos para la lucha canaria. En el año 1937 fue víctima de los trágicos paseíllos y fue arrojado por el desfiladero de la Sima de Jinámar (Tarajano, 1997). Otro luchador del barrio de San José, Juan Correa, fue detenido por su amistad con Florido pero pudo conservar su vida (Padilla, 2004). El clima de sospecha e inseguridad vivido tras el conflicto encuentra otro ejemplo en Manuel Marrero López, Manolito: el exluchador que ejerció la función de dirigente del equipo de lucha de San José y contra quien se alegó afiliación a la Unión Republicana acabó siendo acusado por razones políticas. La condena le hizo perder su empleo y, a partir de entonces, su trayectoria vital estuvo condicionada por el estigma ideológico privándole de trabajo alguno a lo largo de su vida. Resulta significativo que todos los luchadores referidos y perseguidos por la represión franquista procedieran del barrio de San José, en Gran Canaria, lugar que sufrió virulentamente la represión franquista por su complicidad republicana (Padilla, 2004). También, el luchador herreño Bartolomé Fernández Morales, conocido como Bartolomé Guerra, fue víctima de las consecuencias del conflicto bélico al tomar partido por el bando republicano. Al acabar la guerra se exilió en Francia, aunque a su vuelta a España fue encarcelado en un campo de concentración (Sánchez, 1988). En el bando opuesto, existió otro grupo de luchadores identificados como colaboradores franquistas. Luchadores retirados como Silvestre Angulo y Justo Mesa asumieron la organización de eventos luchísticos con el fin de recaudar fondos y apoyar al bando nacional. Este ejemplo empresarial no logró los objetivos previstos (Sánchez, 1988). El alcalde del municipio de Agaete, Fernández de la Torre, fue el artífice de la organización de una luchada que sí cumplió con los fines recaudatorios. La luchada patriótica se celebró bajo la denominación de festival típico deportivo, más acorde con el nuevo lenguaje franquista. En dicho evento destacan las ausencias de luchadores como Santana Florido y Clemente Ríos, evidentes por su adscripción ideológica de izquierda y republicana. El final de Florido ya ha sido relatado. Clemente Ríos fue obligado a formar parte del ejército liderado por Franco y desertó para formar parte del bando republicano Una vez concluida la guerra, afirmó que había sido prisionero republicano y no fue encausado (Falcón, 2001). También destaca como organizador de actos en pro del ejército sublevado el que fuera, en la década de los 60, presidente de la Federación de Lucha Canaria, Luis Doreste Silva, además de ocupar la Dirección del Sindicato Vertical de Iniciativa y Turismo del Gobierno franquista. Otros luchadores que apoyaron la causa nacional fueron M. Caballero Cabrera, el Bicho, J. Rodríguez Franco, el Faro de Maspalomas o Cristóbal Ramos, unos pretendiendo salvar a España y otros luchando contra los comunistas (Sánchez, 1988). 
En torno a las Razones de la Elección de BARCElona COMO SEDE dE LA OlimPIADA POPULAR EN 1936

Existen algunos elementos que pueden ayudar a comprender la elección de Barcelona como sede de una Olimpiada Popular, entre ellos cabe citar su arraigada tradición deportiva, su condición de ciudad industrial/obrera, su entramado social asociativo y su identidad nacionalista (Colomé, 2008). Lo cierto es que Barcelona destacaba por contar con un acervo deportivo peculiar. La condición industrial de la capital catalana, favorecida por unas instalaciones portuarias de primera magnitud, facilitó la consolidación del deporte como una de las actividades de ocio de sus habitantes. El deporte burgués, sobre todo el náutico, encontró un caladero ideal en Cataluña, donde se producía un importante desarrollo tecnológico y germinaban grupos de aficionados, con nuevos hábitos de vida. En lo que a la tradición obrera y asociativa se refiere, en el primer cuarto del siglo xx se desarrollan las organizaciones sindicales obreras, que habían demandado la limitación de la jornada laboral; ello incidió en el tiempo libre de los trabajadores, parte del cual pudieron dedicar a la práctica deportiva. En este contexto Barcelona se erigió como lugar idóneo para contar con el apoyo de los trabajadores en la organización de un evento como la Olimpiada Popular. En este sentido Barcelona destaca por presentar la singularidad de que la tradición deportiva obrera se fraguó más en los ateneos populares, los clubes obreros y las asociaciones deportivas de base que en las internacionales deportivas obreras como sucedía en el resto de Europa, quizás condicionada por su enraizada tradición anarquista.

Otro factor que coadyuvó a que la capital catalana fuera reconocida como sede de la Olimpiada Popular fue el identitario. En los años 20, la supresión de la Mancomunidad de Cataluña impuesta por Primo de Rivera erigió al deporte como catalizador de pulsiones nacionalistas que fueron proyectadas desde la prensa barcelonesa. La instauración de la II República en los años 30 acabó por favorecer que los partidos políticos adoptasen la concepción del deporte como favorecedor de vida sana, además de como aglutinador de lazos grupales.

A nivel estatal la celebración de la Olimpiada Popular se vio reforzada por los resultados de las elecciones del 36, donde la izquierda española se alzó con el poder liderada por un Frente Popular que aglutinaba a las diversas fuerzas de la izquierda española. Colateralmente, las instituciones catalanas volvían a su actividad tras los acontecimientos de 1934, los cuales habían conducido a su interrupción, y recobraban su autonomía favoreciendo un cauce de entendimiento con el poder central. Desde el punto de vista internacional, cabe destacar la correlación electoral que se produce en el país vecino, donde el Frente Popular francés también lleva al poder a socialistas y comunistas dejando de lado los conflictos ideológicos y optando por la unión frente al avance de los movimientos totalitarios en Europa. Ello motivó que la organización de eventos deportivos de carácter obrero no recayese únicamente en las organizaciones sindicales o en los partidos de izquierda, sino que también los gobiernos de algunos países se implicasen en la celebración de dichos acontecimien- 
tos. Un aspecto a destacar acerca de la Olimpiada Popular de Barcelona es que permite apreciar los vínculos de clase y el alcance de la presunta fortaleza de la coalición entre la izquierda europea (Colomé, 2008).

\section{En el centro de la organización de la Olimpiada Popular}

La iniciativa para la organización de la Olimpiada Popular en Barcelona surgió de un grupo de diversos colectivos deportivos y culturales radicados en Barcelona, el Comité Catalá Pro Esport Popular (CCEP), constituido al amparo de la victoria del Frente Popular en el 36. Su meta final era estimular la práctica deportiva entre los trabajadores, transformarse en el núcleo de un movimiento que fomentase el deporte popular catalán. El Comité se declaraba antifascista y pacifista a la par que renegaba de cualquier adscripción con los centros de poder, se trata de una organización que proyectaba los principios del «frentepopulismo deportivo». Entre sus primeras actuaciones destaca el respaldo a un atleta alemán que había sido privado de libertad por comulgar con la ideología comunista. A la postre, la organización de la Copa Thaleman se convirtió en un homenaje a un deportista y en un acto en defensa de la libertad ideológica frente a las políticas discriminatorias del Gobierno nacionalsocialista. Así mismo, la confrontación movimiento cívico versus poder estatal reflejó la tensión que se vivía en Europa con la llegada al poder del partido nazi y donde la organización de la Olimpiada Popular justo tres meses previos a la inauguración de los Juegos de Berlín alcanzó la dimensión de juegos olímpicos paralelos (Colomé, 2008; Pujadas, 2001).

El contexto internacional coadyuvó a la recepción que halló en Europa la propuesta de Olimpiada Popular, sobre todo en Francia. El apoyo incondicional de las organizaciones obreras europeas fue fundamental para la programación del evento popular en Barcelona. La Olimpiada Popular nunca se llegó a celebrar, fue abortada por el pronunciamiento militar, pero su comparación con la Olimpiada Obrera de Amberes de 1932 no se sostiene. Fueron acontecimientos con la misma inquietud pero totalmente diferentes.

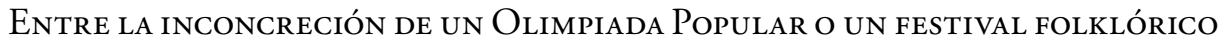

La denominación que se adoptó para designar el evento deportivo a realizar en Barcelona no estuvo exenta de polémica. En el Parlamento catalán no existió unificación de criterios entre sus propios organizadores al referirse al acto deportivo desde la tribuna de oradores, Olimpiada Popular, Semana de Deportes Populares o Semana del Deporte y del Folklore fueron algunas de las referencias entre los parlamentarios socialistas. La inclusión de nominativo folklore ampliaba la percepción del acontecimiento y transcendía lo meramente deportivo, a la vez que conectaba con la idea de popular que se le quería imprimir al acontecimiento deportivo. Un aspecto que se ajustaba a los hechos, ya que entre las delegaciones fueron registradas agrupaciones musicales o grupos de danza. Sin duda, una dimensión acorde 
con una ideología de motivaciones izquierdistas que pretendía destacar todo lo relacionado con el universo del trabajador, del obrero, de lo popular. De ahí que también se incluyeran deportes que no poseían el reconocimiento de deportes olímpicos, como el rugby, el ajedrez, la pelota vasca o la lucha canaria.

La acogida que tuvo la proclama de una Olimpiada Popular, que connotaba una forma de boicot o protesta frente a las inminentes olimpiadas oficiales a celebrar en Berlín, entre el mundo deportivo fue diversa. Por un lado, contó con el apoyo de la Federación Internacional de Marcha pero se lo denegó la Federación Internacional de Atletismo Amateur. En el ámbito nacional, destaca la oposición que mostró la Federación Española de Atletismo. En lo que respecta al Comité Olímpico Espanól, su posición contó con altas dosis de diplomacia, ya que si bien no estaba a favor del evento deportivo catalán tampoco adoptó una oposición tajante (Colomé, 2008).

La lucha Canaria y la cancelación de la Olimpiada Popular de Barcelona 1936

Una de las razones para que la candidatura de Barcelona 1936 fuese desestimada por el Comité Olímpico Internacional fue debido a la coyuntura internacional del momento. La proyección internacional que adquirían las ciudades organizadoras del evento incrementó la competencia de candidatos a albergar unos juegos olímpicos. Las candidaturas que se postulaban junto a Barcelona en 1931 para convertirse en anfitrión olímpico eran Roma y Berlín. La ciudad alemana se vio favorecida por los acuerdos entre Francia y la Alemania de Weimar que proyectaban la idea de un periodo de no beligerancia en Europa. De ahí que la elección de la sede olímpica tuviera fuertes connotaciones políticas con intención de favorecer las buenas relaciones entre los eternos enemigos europeos (Colomé, 2008).

La otra razón apuntada para denegarle a Barcelona su condición olímpica fue la proclamación de la II República y la inestabilidad política y social que siguió a su instauración; esto fue determinante para que la candidatura de Barcelona como sede olímpica en el año 1936 fuera rechazada por el Comité Olímpico Internacional (COI). Tras una primera reunión en Barcelona, en 1931, el Comité Olímpico Internacional no fue capaz de consensuar el lugar para la celebración de las olimpiadas y la decisión final de otorgar los juegos olímpicos a la ciudad alemana de Berlín se adoptó tras una consulta realizada a través del correo postal con 43 votos a favor de la capital alemana frente a 16 a favor de Barcelona (González, 2002; Salvador, 2004). En su defecto, en Barcelona fue organizada una reunión deportiva denominada Olimpiada Popular, que contó con el apoyo del Gobierno republicano (Physick, 2017) y en la que se fijó la fecha de inauguración el 19 de julio de 1936 . El estallido de la guerra civil provocó su suspensión y los atletas de diferentes nacionalidades que esperaban en Barcelona fueron evacuados. El comienzo de la guerra sorprendió a algunos luchadores canarios en el viaje de ida. Este fue el caso de José Suárez Morales, Pelota, y de Lorenzo Anduesa, que habían sido seleccionados por la empresa del puerto de Las Palmas de Gran Canaria para participar en aquella olimpiada de empresa. A su llegada a Cádiz se vieron sorprendidos por el levantamiento 
militar. El temor a ser víctimas de represalias políticas separó a los dos seleccionados canarios. L. Anduesa consiguió atravesar parte del territorio donde ya habían estallado los enfrentamientos bélicos. De regreso en Gran Canaria fue puesto a disposición de las autoridades franquistas y declarado culpable por motivos ideológicos. Tras pasar algún tiempo en la cárcel fue liberado por su vinculación con la lucha canaria. El otro olímpico canario, J. Suárez, optó por exiliarse en Francia y regresó a Canarias en 1976 con los cambios que se avecinaban en el contexto político español (Henríquez, 1990). No obstante, en los años posteriores al final del conflicto, algunos de sus familiares fueron acusados por motivos ideológicos y la mayor parte de su familia fue víctima de la persecución franquista y de la coacción de su libertad (Henríquez, 1996; Padilla, 2004).

Recibido: 10 de mayo de 2019, aceptado: 10 de julio de 2019 


\section{BIBLIOGRAFÍA}

Amador, F. (1996b). «Perspectiva genealógica de la lucha. Su proceso de deportivización. Hacia una clasificación de los deportes de lucha» (pp. 37-73), en Actas del I Congreso Internacional de Luchas y Juegos Tradicionales. Puerto del Rosario (Fuerteventura), Madrid.

Blas, A. y García, R. (1998). Teoría del Estado. Madrid: UNED.

Brito, O. (1989). Canarias, 1931-1936. La Segunda República. S/C de Tenerife: Centro de la Cultura Popular Canaria.

Cabrera, M.A. (1985). La represión franquista en El Hierro (1936-1944). La Laguna: Centro Amílcar Cabral.

Campillo, C., González, P. y Monserrat, J. (2018). «Aproximación historiográfica a la actividad deportiva en España (ss. XIX-Xx): Asociacionismo, institucionalización y normalización», en Materiales para la Historia del Deporte, n. ${ }^{\circ}$ 17, 2018 - ISSN: 2340-7166. Universidad de Alicante. https://www.upo.es/revistas/index.php/materiales_historia_deporte/article/../2692.

CARr, R. (1991). España: de la Restauración a la democracia.1875-1980. Barcelona: Ariel.

Del Águila, R. (1997). Manual de Ciencia Política. Valladolid: Trotta.

Falcón Falcón, J.R. (2001). La lucha canaria: Mandarría, Mederos y compañia. Gran Canaria: Ayuntamiento de Gáldar (Gran Canaria).

Ferrer, M. (ed.) (1993). Lecciones de Historia Reciente de España. Las Palmas de Gran Canaria: Centro de Estudios de Humanidades.

Hernández, Martín y Mateo (2000). Lucha Canaria. Historia, Estructura y Técnica. Santa Cruz de Tenerife: Gobierno de Canarias.

García Ferrando, M. (1990) Aspectos sociales del deporte. Madrid: Alianza.

GonzÁlez AjA, T. (ed.) (2002). Sport y Autoritarismos. Madrid: Alianza.

Hernández Moreno, J. y SÁnchez, S. (1979). Lucha canaria para niños y principiantes. Las Palmas de Gran Canaria: José y Juan Hernández Moreno.

Henríquez Peñate, S. (1986). Historia de la lucha canaria. Telde 1870-1985. Agüimes. Gran Canaria. S.n.

Henríquez Peñate, S. (1996). Arte y vivencia de la lucha canaria. Las Palmas de Gran Canaria. S.n.

Morales, J.V. y Palenzuela, J.M. (2004). La lucha canaria. Santa Cruz de Tenerife: Centro de la Cultura Popular Canaria.

Padilla Quintana, P. (2004). San José, el Adargota y la lucha canaria. Las Palmas de G.C.: Fundación Mapfre Guanarteme.

Payne, S. (2005). El colapso de la Repúblia: los origenes de la guerra civil (1933-1936). Madrid: Ed. La Esfera de los Libros.

Payne, S.G. (2017). En defensa de España. Barcelona: Ed. Espasa.

Physick Ray (2017). «The Olimpiada Popular Barcelona 1936, Sport and Politics in an Age of War, Dictatorship and Revolution» (pp. 51-57). Sport in History, vol. 37, n. ${ }^{\circ} 1$.

PlazAs, G. (2018). «Deporte y política durante la II República y el primer franquismo», en Ernesto Cutillas Orgilés (coord.), Convergencia y transversalidad en humanidades. Actas de las VII Jornadas de Investigación de la Facultad de Filosofía y Letras de la Universidad de Alicante 
(Alicante, 6 y 7 de abril de 2017). Alicante: Facultad de Filosofía y Letras, Universidad de Alicante, 2018. Congresos-Jornadas de Investigación Filosofía y Letras 2017-Libro de Actas.

Rivero Rodríguez, E. (2007). Crónicas de la lucha canaria: historias del tiempo viejo. Tenerife: Centro de la Cultura Popular Canaria.

Rodríguez, A. (2008). El deporte en la construcción del espacio social. Madrid: CIS.

Salvador, J.L. (2004). El Deporte en Occidente. Historia, Cultura y Politica. Madrid: Cátedra.

SÁnchez, S. (1985). La lucha canaria y otras luchas del mundo. Santa Cruz de Tenerife: Centro de la Cultura Popular.

SÁnchez, S. (1988). Historias y vidas. La lucha canaria. Las Palmas de Gran Canaria: Edirca.

Tarajano Mesa, M.A. (1997). El Maninidra: Luchando a orillas del Guayadeque. Las Palmas de Gran Canaria: Ayuntamiento de la Villa de Ingenio.

VArela, S. (1976). El problema regional en la II República española. Madrid: Unión Editorial.

Varela, S. (1978). Partidos y Parlamento en la Segunda República. Barcelona: Ariel. 
